\title{
Eave and swarm collections prove effective for biased captures of male Anopheles gambiae mosquitoes in Uganda
}

\author{
Krystal Birungi', Danspaid P. Mabuka', Victor Balyesima', Annet Namukwaya', Elinor W. Chemoges', \\ Sylvia Kiwuwa-Muyingo ${ }^{2}$, C. Matilda Collins ${ }^{3}$, Frederic Tripet ${ }^{4}$ and Jonathan K. Kayondo ${ }^{1^{*}}$ (B)
}

\begin{abstract}
Background: Traditional malaria vector sampling techniques bias collections towards female mosquitoes. Comprehensive understanding of vector dynamics requires balanced vector sampling of both males and females. Male mosquito sampling is also necessary for population size estimations by male-based mark-release-recapture (MRR) studies and for developing innovations in mosquito control, such as the male-targeted sterile insect technique and other genetic modification approaches. This study evaluated a range of collection methods which show promise in providing a more equal, or even male-biased, sex representation in the sample.
\end{abstract}

Results: Swarms were found at all study sites and were more abundant and larger at the peak of the wet season. Swarm sampling caught the most males, but when man/hour effort was factored in, sampling of eaves by aspiration was the more efficient method and also provided a representative sample of females. Grass-roofed houses were the most productive for eave collections. Overall few mosquitoes were caught with artificial resting traps (clay pots and buckets), although these sampling methods performed better at the start of the wet season than at its peak, possibly because of changes in mosquito ecology and an increased availability of natural resting sites later in the season. Aspiration of bushes was more productive at the peak of the wet season than at the start.

Conclusions: The results of this study demonstrate that eave aspiration was an efficient and useful male mosquito collection method at the study sites and a potentially powerful aid for swarm location and MRR studies. The methods evaluated may together deliver more sex-balanced mosquito captures and can be used in various combinations depending on the aims and ecological parameters of a given study.

Keywords: Malaria, Mosquito sampling, Vector ecology, Resting traps, Swarm sampling, Aspiration, Eave

\section{Background}

Malaria prevention requires studying vector species to understand disease transmission and to effectively implement appropriate vector control. Although malaria control efforts have intensified over the past 10 years, with millions of lives saved $[1,2]$, the effectiveness of mainstay

*Correspondence: jkayondo@uvri.go.ug

${ }^{1}$ Entomology Division, Uganda Virus Research Institute (UVRI), Plot 51-59, P.O. Box 49, Entebbe, Uganda

Full list of author information is available at the end of the article methods, such as insecticide-treated nets (ITNs) and indoor residual spraying (IRS), is decreasing [3, 4]. Insecticide resistance is increasing in mosquito populations, and new tools are urgently needed [5-9]. With new technologies being proposed, such as active genetics (gene drives), and other genetic modification products, it is important to have an understanding of the ecology and biology of vector species that is supported by consistent species-wide sampling techniques $[7,8,10]$. Consistency in these methods will enable the development of comparable baselines and the evaluation of novel interventions. 
Entomological surveillance and population studies for malaria control require comprehensive and strategized field collections for sampling mosquito vectors [11]. To effectively sample mosquito populations, different collection methods and equipment are deployed depending on the aim of the study and the type of information/data required. A variety of collection methods are currently available for sampling adult and immature mosquito stages, which have been described in literature $[12,13]$. Ideally, a representative sample of an adult vector population would contain unfed, blood-fed and gravid females as well as males. However, although a large body of work on mosquito surveillance has been compiled, emanating from decades of vector research and control efforts, the majority of the trapping techniques currently in use are inherently and explicitly targeted at the capture of females-most likely due to the fact that malaria vector control has also focused on the plasmodium-spreading female mosquitoes instead of the males which do not bite.

Mosquito sampling for surveillance and research studies must provide reliable estimations of parameters such as distribution, density and abundance of both indoor and outdoor populations [14]. Indoor resting Anopheles gambiae are commonly sampled using knockdown spray catches, which involves the spraying of insecticide into a room to knock down individuals onto a sheet, enabling collection by hand, or by using mechanical aspirators $[15$, 16]. These approaches predominantly recover females resting after a blood meal and only a small proportion of males. Many collection methods, including those used for outdoor sampling, rely on lures that can be generally classified into biological (human/animal baited collections), chemical (various molecular baits, such as $\mathrm{CO}_{2}$ ), physical (light, heat or color) and combined physicochemical attractants $[9,17,18]$. These also attract mostly host-seeking females in flight that are lured by visual, olfactory and thermal cues, or gravid females seeking to oviposit.

Female Anopheles mosquitoes transmit the malaria parasite when taking a blood feed, males feed only on sugar sources, such as nectar from plants [19]. Thus, mosquito collections conducted with the aim of understanding malaria transmission have traditionally been carried out with tools designed to maximize female captures; however, the collection of male mosquitoes is becoming necessary for many scenarios. For example, when estimating population size by mark-release-recapture (MRR) studies, from an ethical perspective it may be considered more acceptable to make use of males rather than females. Females are a biting nuisance and are potential malaria vectors; also they will probably contribute offspring to the next generation. With collection methods so skewed towards female mosquito collections, it is a possibility that the lack of sufficient males in the catch may skew the arising population size estimates. The sterile insect technique (SIT) and novel male-mediated genetic control approaches have been proposed for Anopheles mosquitoes [20]. Studies to better understand male ecology and reproductive biology in many ecological regions are essential for optimization and future field evaluation of the efficacy of such techniques.

In this study we evaluated a range of mosquito collection methods which might mitigate the female sampling bias. Published literature on and reviews of previous mosquito capture studies were explored and those with the potential for male capture were identified. Other than swarm captures, which are inherently male-targeted, methods focusing on mosquito resting shelters, such as vegetation and eaves, were considered to be potentially productive places to find males, but required empirical assessment [21]. Therefore, in addition to swarm collections, the study focused on clay pot traps, resting bucket traps, house eaves and bush aspiration, all methods which have shown varying degrees of promise for male mosquito capture in other settings [22, 23]. Collections were performed in three mainland villages in Uganda and the methods of capture compared in terms of the species captured, the sex ratio of $A$. gambiae samples and females and males capture rates per unit of capture and/or time.

\section{Methods \\ Study design}

In Uganda, the prevalent mosquito species responsible for the spread of malaria is Anopheles gambiae (s.l.) (A. gambiae) [24]. Five mosquito collection methods, all previously identified for their potential to catch male $A$. gambiae according to the literature review, were selected for evaluation at three village study sites in mainland Uganda. In 2017, two rounds of collections were made. The first collection round was at the start of the rainy season, targeting the early mosquito population period, and the second was at the peak of the rainy season, targeting higher mosquito numbers.

\section{Study sites and descriptions}

The study villages were Kibbuye (KY) and Katuuso (KT) in Mukono district, and Kayonjo (KJ) in Kayunga district (Fig. 1). The villages are located in central Uganda and typically experience two rainy seasons and two dry seasons per year. The first rainy season is generally from March to June, followed by a dry season from July to September. The second shorter rainy season runs from October to November and is followed by a dry period from December to February. All three sites record high 


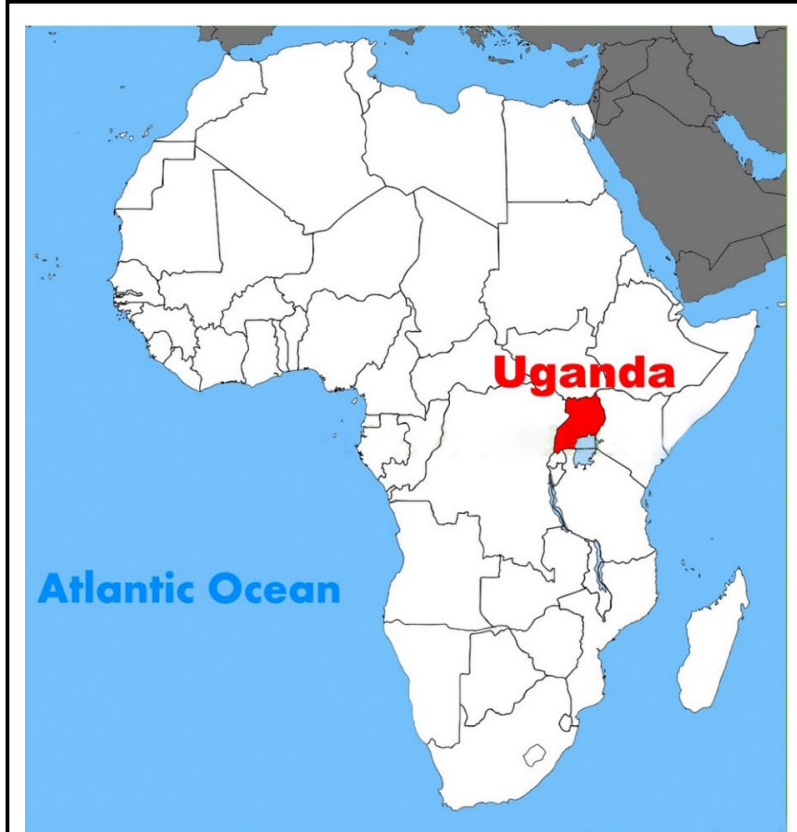

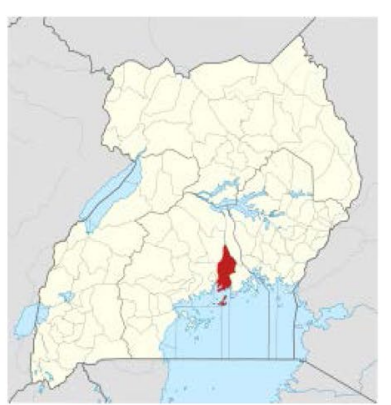

Mukono District

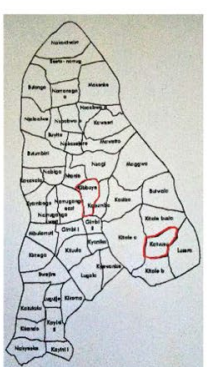

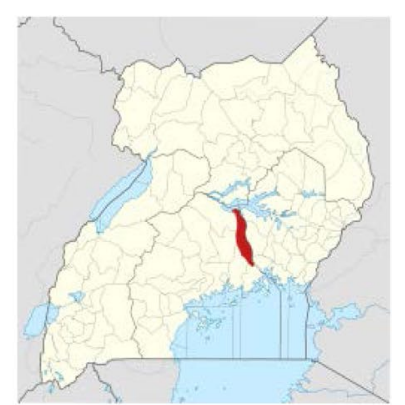

Kayunga District
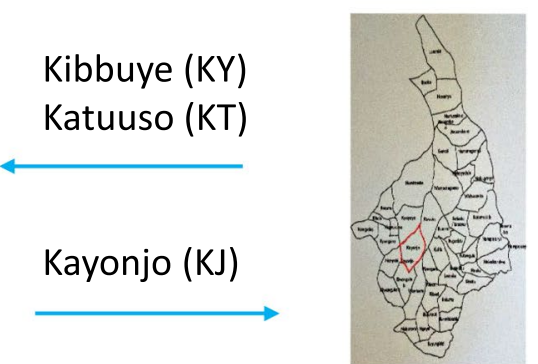

Fig. 1 Location of the study sites in Uganda. The study villages of Kibbuye ( $K Y$ ) and Katuuso $(K T)$ are in Mukono district and Kayonjo $(K J)$ is in Kayunga district

malaria incidence (up to 150 confirmed malaria cases per 1000 population/year) and are located in areas in Uganda that have high malaria endemicity [24].

\section{Kibbuye village}

Kibbuye village is located in Seeta-namuganga subcounty, Mukono district $\left(0.724^{\circ} \mathrm{N}, 32.784^{\circ} \mathrm{E}\right)$ and has approximately 1500 inhabitants. The major economic activity is agriculture, and residents plant rice gardens in the swampy areas bordering the village and coffee plants within the village. In addition to crop farming, some villagers also keep livestock such as cows, pigs and goats on a small scale, with each family owning on average fewer than ten animals. The major bushy vegetation is coffee plants, which are abundant throughout the village. Most mosquito larval habitats are found in the rice gardens but they are also found in local rock pools of collected rainwater.

\section{Katuuso village}

Katuuso village is also located in Seeta-namuganga subcounty, about $7 \mathrm{~km}$ southeast of Kibbuye $\left(0.699^{\circ} \mathrm{N}\right.$, $\left.32.843^{\circ} \mathrm{E}\right)$, Katuuso has approximately 800 inhabitants. The major economic activity is again agriculture, with gardens located throughout the swampy areas bordering the village. While there is some rice farming in Katuuso village, various annual food crops, such as sweet potatoes and maize, are also common. A few families also keep cows, pigs and goats, owning on average, fewer than five animals. As in Kibbuye, coffee plants are abundant in Katuuso, although on a smaller scale. The mosquito larval habits are located in the crop gardens.

\section{Kayonjo village}

Kayonjo village is located in Busaana subcounty of Kayunga district $\left(0.925^{\circ} \mathrm{N}, 32.862^{\circ} \mathrm{E}\right)$ and has approximately 1800 inhabitants. Kayonjo is located approximately $10 \mathrm{~km}$ east of Kibbuye and Katuuso. It is similar to the other study villages in that the major economic activity is agriculture and the areas bordering the village are mostly large tracts of swampy ground on which residents farm. Agriculture here is diverse, with a wide range of food crops such as maize, sweet potatoes, rice and yams. Coffee plants are also abundant in addition to large evergreen trees. Most trees are fruit trees with mango trees especially plentiful. Livestock farming in Kayonjo is mainly on a subsistence basis with most households owning only one or two cows. The swampy gardens once again contain the majority of mosquito larval habitats.

\section{Sampling approach}

Two field sampling visits were made in the three villages, the first at the start of the rainy season and the second at 
its peak. The trips took place from 27 March to 8 April 2017 (start of rainy season) and from 22 May to 3 June 2017 (peak of the rainy season).

The study sites were sampled sequentially during each collection trip, starting with Kibbuye village and ending with Kayonjo village. Each village was sampled over a 2-day period during each collection trip using the methods described below. The locations sampled were the same for each visit. Swarm sampling took place at dusk, but for all other methods, sampling took place in the early morning, which is considered optimal for mosquito collection [25]. For some methods (EAV, CPT, RBT and BUSH, see below), repeat collections at the same sites took place later in the day, typically early to midafternoon in in an effort to ascertain whether mosquitoes continued to move to resting places later in the morning and could have been missed in the initial early morning collection.

\section{Aspiration of eaves}

Ten houses, evenly distributed around each village, were selected for mosquito collection using the

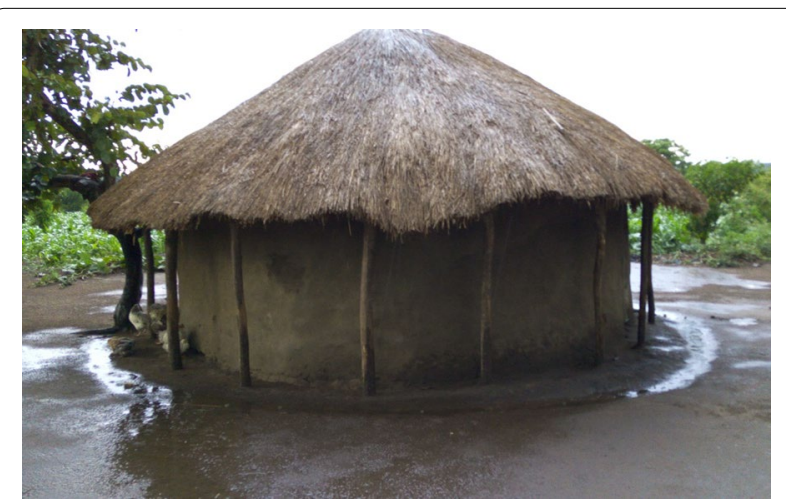

Fig. 2 Typical house used for aspiration of eaves. Of the 30 houses selected for eave aspiration, 24 had mud walls with grass-thatched, overhanging roofs and six were similar but with iron-sheet roofing material aspiration of eaves (EAV) method. The village was stratified into five approximately equal sections, then two grass-thatched houses (Fig. 2) were randomly selected from each section. In cases where no grass-thatched house was available, iron sheet-roofed houses with mud walls were selected. Each house was sampled early in the morning $(06: 00 \mathrm{~h})$ which is the optimal time to capture resting mosquitoes. Two collectors equipped with Prokopack aspirators (model 1419; John W. Hock Co., Gainesville, FL, USA) collected mosquito samples in each village, one collector per house. A timed 10-min sampling system was used to ensure standardization of the collection effort. The collector tried to aspirate the entire eave area as exhaustively as possible by moving the aspirator nozzle back and forth over the collection area while slowly moving around the house. Samples were then labeled and stored for later identification and analysis.

\section{Indoor aspiration of houses}

In each village ten houses were selected for mosquito collection using the indoor aspiration of houses (ASP) method by stratified randomization to proportionately represent the house types and spatial area of the village (Table 1). Three house types were present in Katuuso and Kibbuye (Table 1). In Kayonjo, fired bricks are not used as construction material for domestic buildings but reserved for community buildings such as schools and religious buildings. Aspiration started at 06:00 h. If houses had more than one interior room, only one room (the sleeping room) was aspirated. Two collectors equipped with Prokopack aspirators collected mosquito samples in each village. A timed 10-min sampling system was used. The collector aspirated the entire room as exhaustively as possible by moving the aspirator back and forth over the walls, interior eaves, under furniture and over the interior of the roof. Samples were then labeled for later identification and analysis.

Table 1 Distribution of house types where indoor (interior) and eave aspirations were performed in the three villages

\begin{tabular}{|c|c|c|c|c|c|c|}
\hline \multirow[t]{4}{*}{ Village } & \multicolumn{6}{|c|}{ House type } \\
\hline & \multicolumn{2}{|c|}{ Walls: mud brick } & \multicolumn{2}{|c|}{ Walls: mud brick } & \multicolumn{2}{|c|}{ Walls: brick } \\
\hline & \multicolumn{2}{|c|}{ Roof: grass thatch } & \multicolumn{2}{|c|}{ Roof: iron sheets } & \multicolumn{2}{|c|}{ Roof: iron sheets } \\
\hline & Interior & Eaves & Interior & Eaves & Interior & Eaves \\
\hline Kibbuye & 2 & 7 & 4 & 3 & 4 & 0 \\
\hline Katuuso & 1 & 8 & 6 & 2 & 3 & 0 \\
\hline Kayonjo & 2 & 9 & 8 & 1 & 0 & 0 \\
\hline All & 5 & 24 & 18 & 6 & 7 & 0 \\
\hline
\end{tabular}




\section{Aspiration of clay pots and resting bucket traps}

For the aspiration of clay pots (CPT) method, ten clay pots were locally manufactured following the design adopted from Odiere et al. [22]. This design was slightly modified by reducing the pot mouth to $10 \mathrm{~cm}$ in diameter from $20 \mathrm{~cm}$ (Fig. 3). The pots were unpainted, fired clay of approximately 20-1 capacity. Holes (diameter $2 \mathrm{~cm}$ ) were bored into the bottom of the pots to discourage theft by making the pots unable to store water.

Ten resting bucket traps (RBTs) (Fig. 3) were made following guidelines of Kreppel et al. [26]. A standard 20-1 plastic bucket was lined with wet, black cotton fabric to increase humidity. The buckets were modified by puncturing nail holes in the bottom and sides to discourage theft as described above.

Clay pots and RBTs were placed $5 \mathrm{~m}$ from each house used for indoor aspiration (Table 1) but on opposite sides and left overnight before the first sample was taken. One collector equipped with a Prokopack aspirator collected mosquitoes from each trap type in each village. A timed, 2-min sample was taken from each pot. The aspiration started at the mouth of the pot, gradually moving deeper within the pot. Aspiration of the resting shelters was carried out between 06:00 $\mathrm{h}$ and 08:00 $\mathrm{h}$. Samples were then labeled for later identification and analysis.

\section{Aspiration of bushes}

The aspiration of bushes (BUSH) method was used to collect mosquitoes from 15 bushes around each village using a CDC backpack aspirator (model 1412; John W. Hock Co.). Bushes were selected in a stratified random way by location to provide even coverage of the village area. Bushes were mainly midsized shrubs approximately
$1 \mathrm{~m}$ in height (or less) and $1 \mathrm{~m}$ across (or less). Bush aspirations were carried out between 06:00 $\mathrm{h}$ and 08:00 $\mathrm{h}$ by a single collector in each village. The collector took a 15-min aspiration sample from each bush moving from top to bottom while slowly circling the plant. Samples were then labeled for later identification and analysis.

\section{Swarm collection sampling}

For swarm collection sampling (SWN), each village was notionally divided into two halves and mosquitoes were collected from each half during two sequential days in each survey. Swarm collections were made following the method described by Diabate et al. [27]. Swarm collectors worked in pairs, locating points of contrast on the ground at around 18:00 $\mathrm{h}$ and watching the spaces above these markers against the lighter background of the sky at dusk. When a swarm was seen, the collectors made multiple sweeps of the swarm using a sweep net until the end of the swarming period at complete sunset. Each net with a collection was labeled with the location of the swarm, estimated swarm size, height of swarm above ground and any landmark associated with it, and then stored for later identification. The following morning, the collected mosquitoes were aspirated and, if still alive, killed with chloroform.

\section{Mosquito identification and processing}

All collected mosquitoes were identified to morpho-species in the field by a trained entomologist equipped with a microscope and a morphological key [28]. Identified samples were then placed in a clearly labeled $1.5-\mathrm{ml}$ tube and stored in $80 \%$ ethanol for transport to the laboratory at the Uganda Virus Research Institute (UVRI) for
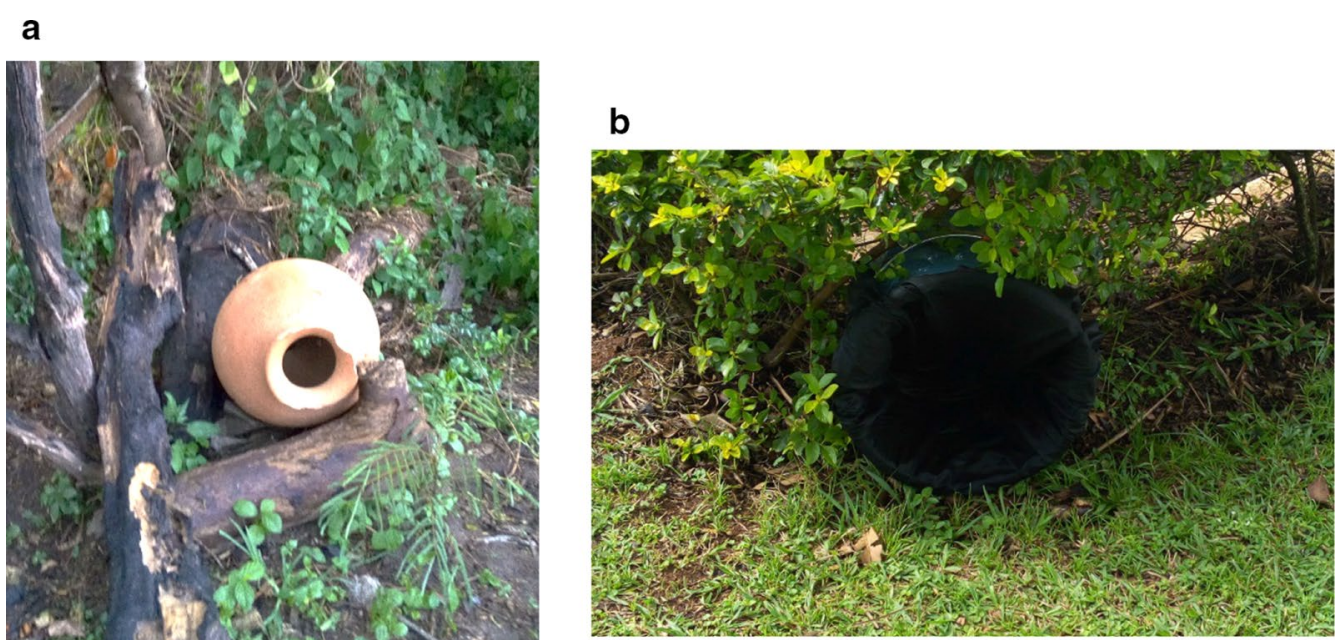

Fig. 3 Clay pot (a) and resting bucket trap (b). These were deployed in pairs, $5 \mathrm{~m}$ from each other, on opposing sides of selected houses throughout each village 
molecular confirmation of morphological identification by PCR using the protocol described by Wilkins et al. [29]. The PCR cycling conditions were melting at $95{ }^{\circ} \mathrm{C}$ for $5 \mathrm{~min}$; then $95{ }^{\circ} \mathrm{C} / 30 \mathrm{~s}, 58{ }^{\circ} \mathrm{C} / 30 \mathrm{~s} 72{ }^{\circ} \mathrm{C} / 30 \mathrm{~s}$ for 30 cycles; followed by 1 cycle of $72{ }^{\circ} \mathrm{C}$ for $5 \mathrm{~min}$. Each reaction comprised template DNA (2 ng), primers $(1 \mu \mathrm{M})$, $\mathrm{MgCl}_{2}(0.3 \mathrm{mM})$, dNTPs $(0.08 \mathrm{mM})$, Taq polymerase (1U), Go Green Taq buffer $(1 \times)$ and distilled $\mathrm{H}_{2} 0$ topped to $25-\mu \mathrm{l}$ total reaction volume. PCR products $(10 \mathrm{ul})$ were observed by separation on agarose (1\%) TBE gels run in $0.5 \times$ TBE buffer at $12 \mathrm{~V} / \mathrm{cm}$, and fragment sizes were estimated using a 1-kb ladder marker. The primers used were IMP-UN, QD-3T, ME-3T GA-3T and AR-3T.

\section{Statistical analysis}

All collected data were analyzed using JMP version 14 software (SAS Institute, Inc., Cary, NC, USA) [30]. Analyses were conducted using parametric and non-parametric methods as appropriate.

For each method of capture and season, the sum of captured A. gambiae (s.l.) male and female mosquitoes, as well as those of Aedes spp., Culex spp. and Mansonia spp., was calculated. Some differences in mosquito abundance were expected among the villages sampled arising from, for example, their geography and water availability, but their extent could not be predicted. In order to estimate the influence of any variation detected, appropriate linear models with main effects and interaction terms were fitted to the data. Non-significant interactions were removed from models following a stepwise approach.

\section{Total number of A. gambiae (s.l.) captured}

The total number of individuals captured per method were compared using frequency tests and likelihood test on odds ratios (ORs) for the data collected during early and peak rainy seasons.

\section{Proportion of males}

Pairwise post-hoc comparisons between methods were performed using likelihood tests on ORs. In order to identify which methods produced sex-biased or more balanced catches, as distinct from the numbers caught, the proportion of A. gambiae males captured was investigated as a function of village, season and method of capture using a binomial generalized linear model (GLM). The data was also analyzed for each season separately. Following this, two dependent variables particularly relevant to field entomologists were calculated and analyzed. The first was the number of females and males captured per unit of collection method, i.e. per room, eaves, per bush aspirated or per trap (clay pot, resting bucket) or per swarm netted. This variable therefore informs the number of collections needed with a given method to collect a given number female or male mosquitoes (e.g. number of house aspirations or clay pots). The second variable takes into account the human resources needed by estimating the yield or number of mosquitoes per unit of collection described above, calculated per number of man hours required to perform such sampling.

\section{Mosquito numbers caught per collection}

The influence of the factors village, method and season, and their interaction, on the number of females and males caught per unit of collection was analyzed using GLMs with Poisson distribution and correction for overdispersion. The data was also analyzed for each season separately. The statistical significance of interactions was tested, but these interactions were removed in a stepwise manner if non-significant. Post-hoc pairwise group comparisons were performed using model contrasts.

\section{Yield (mosquitoes caught per man hour)}

Yield was analyzed using GLMs with Poisson distribution and correction for over-dispersion. The data were also analyzed for each season separately. The statistical significance of interactions was tested but these interactions were removed in a stepwise manner if non-significant. Post-hoc pairwise group comparisons were performed using model contrasts.

\section{Analysis of mosquito yield by house type}

Because of greatly imbalanced sample sizes, unequal variance and non-normality, non-parametric Kruskal-Wallis tests were used to test the effect of each house type on the female and male yield per hour for indoor indoor and eave aspirations.

\section{Results}

\section{Afternoon sampling}

In one of 223 repeat samples taken in the early afternoon, only one mosquito was found (1 female A. gambiae), collected using the EAV method. These afternoon samples, which strongly indicate a lack of daytime mobility in these mosquitoes, were therefore not included in the general data frame.

\section{Overall catch counts and species composition}

A total of 2769 mosquitoes were caught during the two surveys, of which $86 \%(n=2769)$ were A. gambiae (s.l.), $13 \%(n=409)$ were Culex spp., $<1 \%(n=30)$ were Aedes spp. and $<1 \%(n=10)$ were Mansonia spp. (Table 2; Fig. 4). Of the A. gambiae (s.l.) mosquitoes captured, $67 \%$ were male $(n=1841)$ and $33 \%$ were female $(n=928)$ (Table 2), reflecting that our choice of methods was geared towards male captures. The mosquitoes captured from Katuuso and Kibbuye villages comprised 100\% A. 
Birungi et al. Parasites Vectors

(2021) 14:281

Page 7 of 17

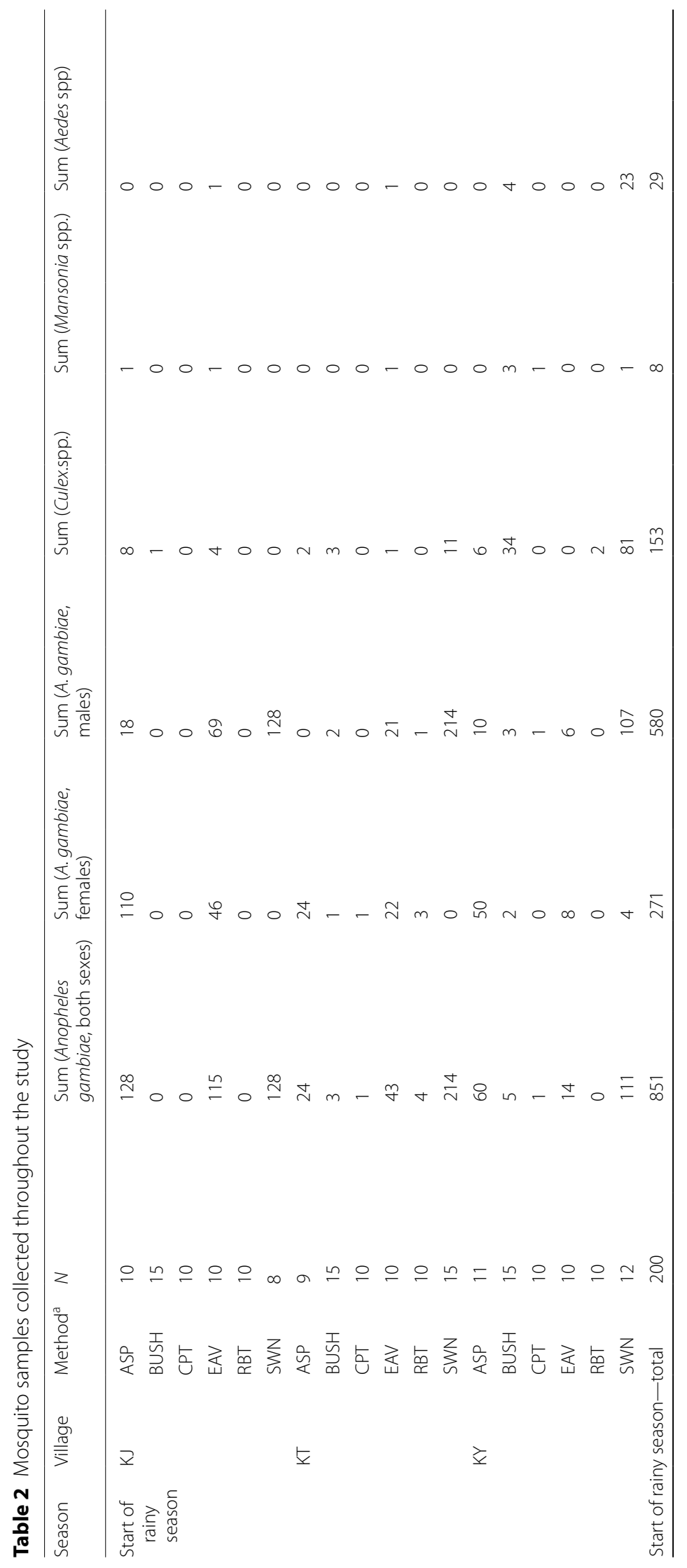




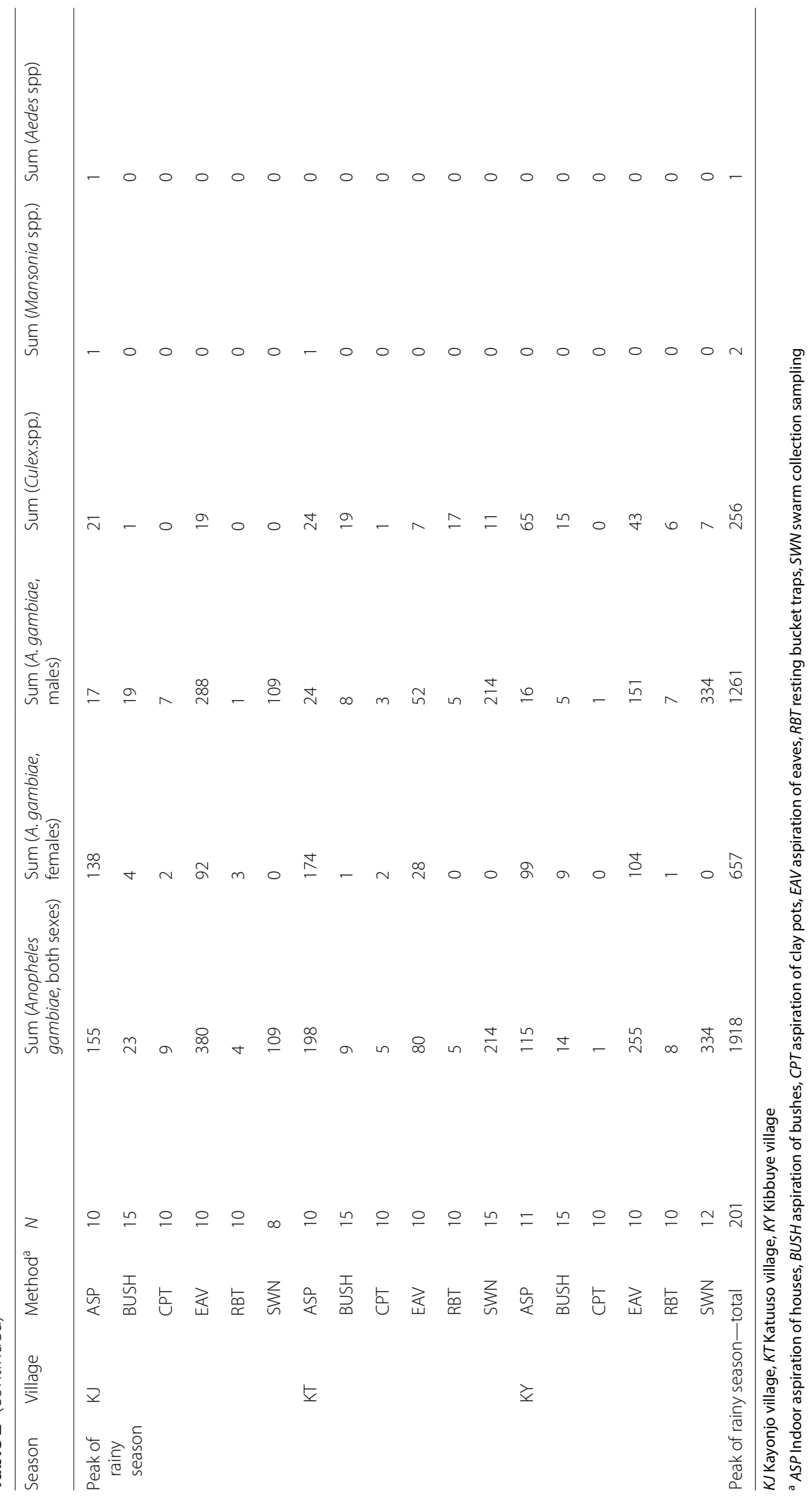




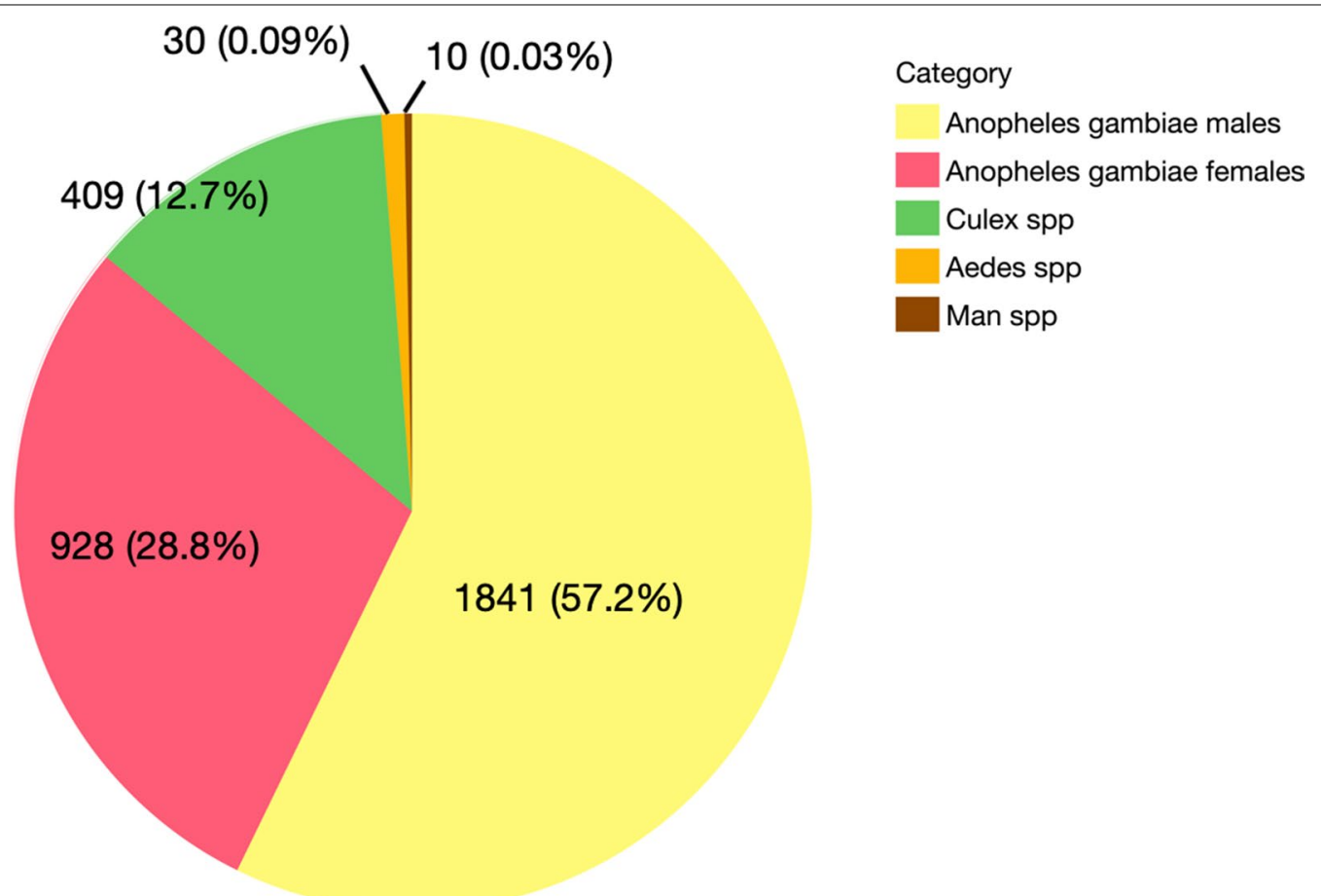

Fig. 4 Number and percentage of female and male Anopheles gambiae (s.l.) mosquitoes and other mosquito species captured during the entire study period. Man Mansonia

gambiae; in contrast, only a very small percentage of the mosquitoes captured in Kayonjo village were $A$. arabiensis $(<1 \%, n=12)$, with the rest made up of $A$. gambiae.

\section{Effect of method on number and male proportion of $A$. gambiae (s.l.) captured}

A total of 851 A. gambiae (s.l.) were captured at the start of the rainy season (Table 2; counts per village, per season per method). Overall, a significantly larger proportion of individuals (53\%) were collected using SWN than with the other methods (likelihood test on ORs: $P<0.0001$ ). The EAV and ASP methods caught 25 and $20 \%$ of the total number of A. gambiae (s.l.), respectively; these two methods differed significantly in terms of number captured from each other and from the other methods $(P<0.001$ in all comparisons). The least effective methods of capture were the BUSH (1\%), RBTs and CPTs methods (both $<1 \%$ ); these latter two methods did not differ in terms of number of $A$. gambiae (s.l.) caught $(P>0.05)$ (Table 2; Fig. 5). A much larger number of $A$. gambiae (s.l.) $(n=1918)$ were captured at the peak of the rainy season (Table 2). At that time, the EAV and SWN methods captured comparable numbers of individuals (37 and $34 \%$, respectively) $(P=0.1175)$, with ASP the next most effective method (25\%). The least effective methods of capture were again the BUSH (2\%) and RBT and CPT methods (both $<1 \%$ ) (Table 2; Fig. 5).

Overall, the proportion of males caught did not vary between the three villages but it did change with the season, increasing from $66 \%$ in the early season to $68 \%$ at the peak season $(P<0.001)$ (Tables 3,4$)$. The different methods of capture resulted in different proportions of males although these proportions varied slightly between villages $(P<0.001)$ (Tables 3,4$)$. A comparison of all capture methods showed that overall, a lower proportion of males was caught with the ASP method (likelihood test on ORs: $P<0.0001$ in all pairwise comparisons) and a greater proportion of males was caught with the SWN method ( $P<0.0001$ in all cases) (Fig. 5). The proportion of males captured by all other sampling methods was intermediate and there was no evidence of variation among them ( $P>0.3511$ in all cases) (Fig. 5). Separate independent analyses of the early and peak seasons led to the same conclusions on these methods of capture.

\section{Number of A. gambiae (s.l.) mosquitoes caught per collection method}

Overall, the numbers of male mosquitoes caught per unit (sample) of each collection method (e.g. per house aspiration, per clay pot, per swarm) varied between villages, but there was no evidence of this variation for 


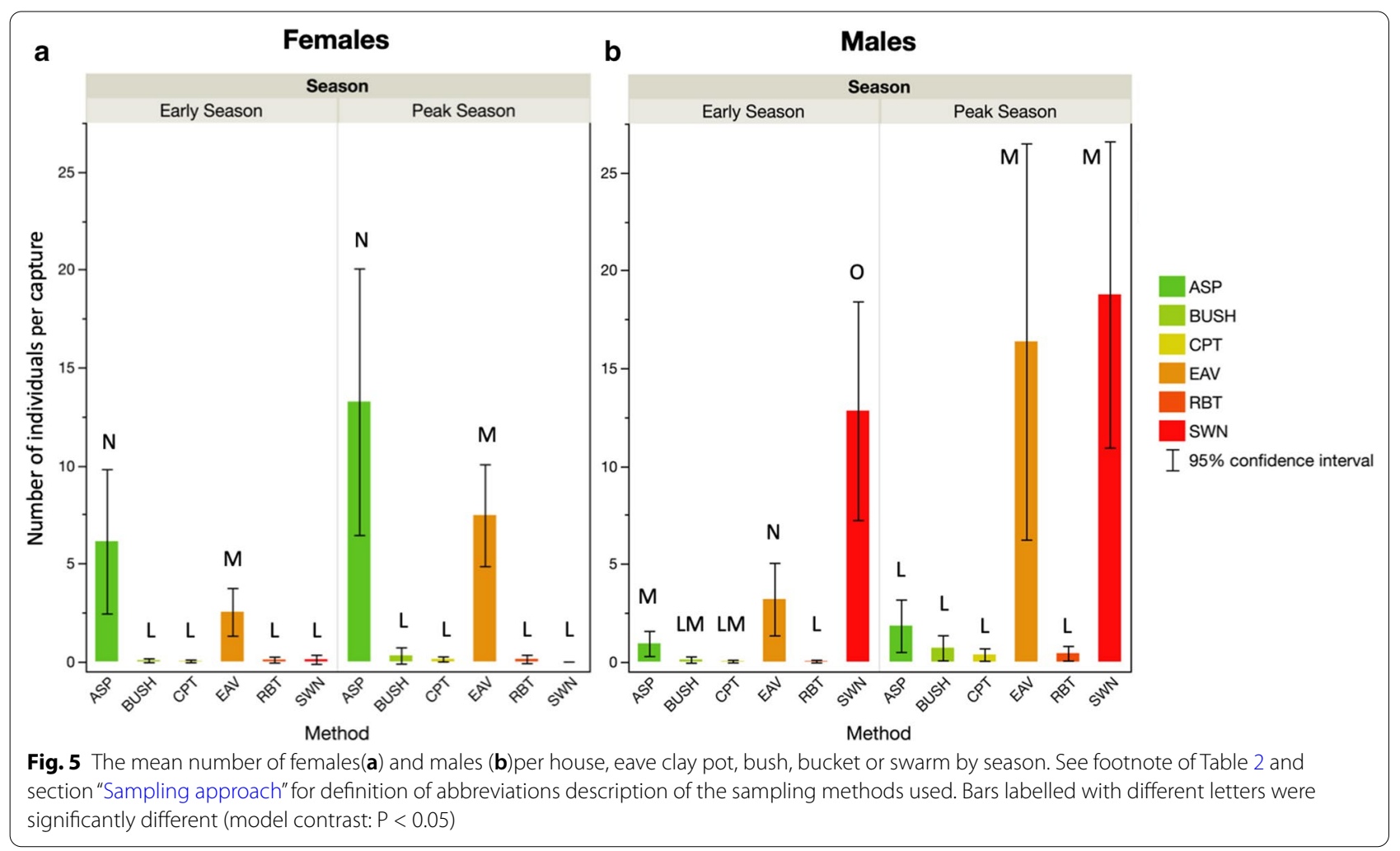

Table 3 Summary statistics of the binomial generalized linear model used to estimate the influence of season, village and method on the proportion of Anopheles gambiae male mosquitoes captured

\begin{tabular}{lllc}
\hline Source & $d f$ & L-R Chi square $^{\mathrm{a}}$ & $P$-value \\
\hline Season & 1 & 13.5 & 0.0002 \\
Village & 2 & 0 & 1.000 \\
Method & 5 & 1657.2 & $<0.0001$ \\
Village $\times$ Method & 8 & 4.5 & 0.0003
\end{tabular}

Main effects and statistically significant, or near-significant, interactions are shown

${ }^{a}$ Likelihood ratio Chi-squared statistic

female mosquitoes (Tables 5, 6). The numbers of A. gambiae male and female mosquitoes captured per method increased from the early to peak rainy season. There was evidence of variation in the response to season between villages for the numbers of males, but not for females (Tables 5, 6). For both sexes, the method used explained by far the largest proportion of variation in the numbers collected per unit (Tables 5, 6; Fig. 6). For females, more individuals were captured with the ASP method than with any of the other methods, and this was true in both seasons (model contrasts: $X^{2}>75.0 P<0.0002$ in all pairwise comparisons). The next most productive method
Table 4 Post-hoc pairwise comparisons (likelihood test on odds ratios) of the proportion of $A$. gambiae female and male mosquitoes collected by the different methods

\begin{tabular}{lcrcc}
\hline Comparison & Odds ratio & P-value & Lower 95\% Cl & Upper 95\% Cl \\
\hline BUSH vs ASP & 16.24 & $<0.0001$ & 7.95 & 33.19 \\
CPT vs ASP & 10.77 & $<0.0001$ & 4.09 & 28.35 \\
CPT vs Bush & 0.66 & 0.4876 & 0.21 & 2.11 \\
EAV vs ASP & 11.66 & $<0.0001$ & 8.82 & 15.43 \\
EAV vs Bush & 0.72 & 0.3511 & 0.36 & 1.44 \\
EAV vs CPT & 1.08 & 0.8704 & 0.42 & 2.81 \\
RBT vs ASP & 12.55 & $<0.0001$ & 4.53 & 34.78 \\
RBT vs BUSH & 0.77 & 0.6746 & 0.23 & 2.57 \\
RBT vs CPT & 1.17 & 0.8266 & 0.30 & 4.57 \\
RBT vs EAV & 1.08 & 0.8863 & 0.39 & 2.94 \\
SWN vs ASP & 996.49 & $<0.0001$ & 466.43 & 2128.92 \\
SWN vs BUSH & 61.37 & $<0.0001$ & 22.77 & 165.37 \\
SWN vs CPT & 92.49 & $<0.0001$ & 28.30 & 302.24 \\
SWN vs EAV & 85.43 & $<0.0001$ & 40.71 & 179.28 \\
SWN vs RBT & 79.39 & $<0.0001$ & 23.26 & 270.96 \\
\hline
\end{tabular}

$\mathrm{Cl}$ Confidence interval

was the EAV method, which caught higher numbers than the remaining methods in both seasons $\left(\chi^{2}>17.1\right.$, $P<0.0001$ for all significant comparisons) (Fig. 6). There was no evidence of variation between the RBT and 
Table 5 Summary statistics of the generalized linear model (Poisson distribution with over-dispersion) used to estimate the influence of season, village and method on the number of A. gambiae female and male mosquitoes collected per unit of collection (room, eaves, bush, bucket, pot, swarm)

\begin{tabular}{lllrr}
\hline Sex & Source & $d f$ & L-R Chi square $^{\mathrm{a}}$ & \multicolumn{1}{c}{$P$-value } \\
\hline Females & Season & 1 & 23.3 & $<0.0001$ \\
& Village & 2 & 5.7 & 0.0593 \\
& Method & 5 & 288.1 & $<0.0001$ \\
\multirow{4}{*}{ Males } & Season & 1 & 7.6 & 0.0058 \\
& Village & 2 & 8.4 & 0.0152 \\
& Method & 5 & 281.7 & $<0.0001$ \\
& Season $\times$ Village & 2 & 7.7 & 0.0215 \\
& Season $\times$ Method & 5 & 12.2 & 0.0325
\end{tabular}

Main effects and statistically significant, or near-significant, interactions are shown

${ }^{\text {a }}$ Likelihood ratio Chi-squared statistic

CPT methods, swarm collections (SWN) and the BUSH method, which all captured low numbers of female mosquitoes regardless of season (model contrasts: $P>0.05$ in all comparisons) (Fig. 6).

When collecting male mosquitoes, the SWN and EAV methods performed better than the other methods overall (model contrasts: $X^{2}>6.1, P<0.0134$ in all cases). There was some seasonal variation and more males were captured with the SWN method compared to the EAV method at the start of the rainy season $\left(\chi^{2}=16.2\right.$, $P<0.0001)$, but not at its peak $(P>0.05)$ (Fig. 6$)$.

\section{Mosquito yield per man/hour effort}

Female mosquito yield (i.e. the number of female mosquitoes caught per unit of collection corrected for man hour effort) did not differ between villages but did vary between seasons and with the method used (Tables 7, 8). Yield per man hour was higher at the peak of the rainy season than at the start (Tables 7, 8; Fig. 7). Overall, the ASP and EAV methods yielded more females per man hour than the other methods tested (model contrasts: $X^{2}=57.9, P<0.0001$ for all pairwise comparisons). This pattern was observed both at the start and peak of the rainy season $(P<0.001$ in all cases) (Fig. $7 \mathrm{a})$, although at the peak of the rainy season, female yield by ASP was higher than that of $\operatorname{EAV}\left(\chi^{2}=6.5, P<0.0108\right)$.

Male mosquito yield was greater at peak season and differed between villages (Tables 7,8 ). Once again, the method had the largest effect on the yield per man hour (Tables 7, 8; Fig. 7). For males, SWN and EAV showed the higher collection efficiency at the start of the rainy season, while all the other methods performed similarly $\left(X^{2}<8.1, P<0.0044\right)$ (Fig. 7). However, at the peak of the
Table 6 Post-hoc pairwise comparisons (generalized linear model contrasts) of the number of A. gambiae female and male mosquitoes collected per unit of collection (room, eaves, bush, bucket, pot, swarm) using different methods

\begin{tabular}{|c|c|c|c|c|}
\hline Comparison & Value & Log-likelihood & Chi-square & $P$-value \\
\hline \multicolumn{5}{|l|}{ Females } \\
\hline BUSH-ASP & 3.94 & 200.41 & 137.62 & $<0.0001^{*}$ \\
\hline CPT-ASP & 4.76 & 187.49 & 111.78 & $<0.0001^{*}$ \\
\hline CPT-BUSH & 0.82 & 131.81 & 0.43 & $<0.0001^{*}$ \\
\hline EAV-ASP & 0.67 & 138.44 & 13.68 & $=0.0002^{*}$ \\
\hline EAV-BUSH & 3.28 & 163.47 & 63.75 & $<0.0001^{*}$ \\
\hline EAV-CPT & -4.09 & 158.87 & 54.54 & $<0.0001^{*}$ \\
\hline RBT-ASP & 4.42 & 186.34 & 109.49 & $<0.0001^{*}$ \\
\hline RBT-BUSH & 0.48 & 131.69 & 0.18 & $=0.6721$ \\
\hline RBT-CPT & -0.34 & 131.62 & 0.05 & $=0.8246$ \\
\hline RBT-EAV & 3.76 & 157.91 & 52.63 & $<0.0001^{*}$ \\
\hline SWN-ASP & 5.09 & 192.27 & 121.34 & $=0.4325$ \\
\hline SWN-BUSH & 1.15 & 131.98 & 0.77 & $=0.3805$ \\
\hline SWN-CPT & 0.33 & 131.62 & 0.04 & $=0.8501$ \\
\hline SWN-EAV & 4.42 & 161.62 & 60.06 & $<0.0001^{*}$ \\
\hline \multicolumn{5}{|l|}{ Males } \\
\hline BUSH-ASP & 1.54 & $-^{\mathrm{a}}$ & 3.32 & $=0.0685$ \\
\hline CPT-ASP & 2.48 & - & 2.13 & $=0.1448$ \\
\hline CPT-BUSH & 0.93 & - & 0.26 & $=0.6092$ \\
\hline EAV-ASP & -1.71 & - & 17.57 & $<0.0001^{*}$ \\
\hline EAV-BUSH & -3.25 & - & 17.18 & $<0.0001^{*}$ \\
\hline EAV-CPT & -4.18 & - & 6.29 & $=0.0122$ \\
\hline RBT-ASP & 2.39 & - & 2.01 & $=0.1563$ \\
\hline RBT-BUSH & 0.85 & 166.04 & 0.29 & $=0.5937$ \\
\hline RBT-CPT & -0.08 & 165.90 & 0.001 & $=0.9715$ \\
\hline RBT-EAV & 4.10 & - & 6.12 & $=0.0134$ \\
\hline SWN-ASP & -2.53 & - & 44.21 & $<0.0001^{*}$ \\
\hline SWN-BUSH & -4.07 & - & 27.92 & $<0.0001^{*}$ \\
\hline SWN-CPT & -5.00 & - & 9.06 & $=0.0026^{*}$ \\
\hline SWN-EAV & -0.89 & - & 16.24 & $=0.0001^{*}$ \\
\hline SWN-RBT & -4.92 & - & 8.88 & $=0.0029^{*}$ \\
\hline
\end{tabular}

*Significant difference between methods

${ }^{a}$ Dash (-) in cells indicates missing values of - log likelihood, indicating that a suboptimization step failed to converge. In these cases, a Wald test statistic was used and a $P$-value provided rather than a likelihood ratio test

rainy season, EAV had a higher yield than all other collection methods $\left(X^{2}>31.0, P<0.0001\right)$, achieving the capture of $>60$ male mosquitoes per hour of sampling (Fig. 7).

\section{Effect of house construction type on yield}

The house construction type affected the yield of house aspirations for males (Kruskal-Wallis: $\chi^{2}=25.0$, $P<0.001)$. Houses built with mud walls and grassthatched roofs led to higher yields of male mosquitoes than houses built with brick walls and iron sheet roofs 


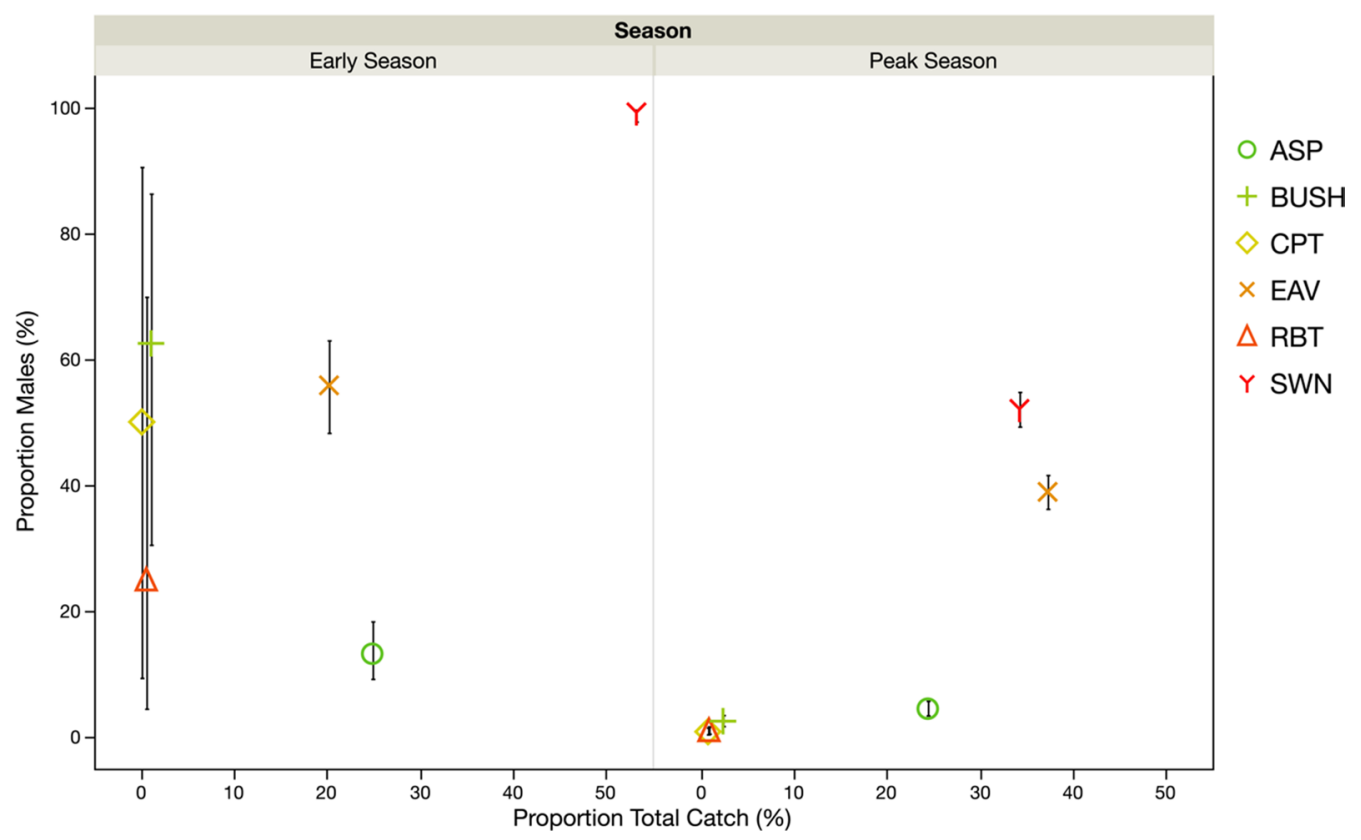

Fig. 6 Proportions of A. gambiae (s.l.) caught using the different methods and corresponding proportion (\%) of male mosquitoes captured, by season. The error bars indicate the confidence intervals around the estimates of sex ratio

Table 7 Summary statistics of the generalized linear model used to estimate the influence of season, village and method on the yield per man hour of A. gambiae female and male mosquitoes collected

\begin{tabular}{lllcr}
\hline Sex & Source & $D F$ & L-R Chi square & P-value \\
\hline Females & Season & 1 & 37.5 & $<0.0001$ \\
& Village & 2 & 1.7 & 0.4362 \\
& Method & 5 & 261.5 & $<0.0001$ \\
\multirow{3}{*}{ Males } & Season & 1 & 50.7 & $<0.0001$ \\
& Village & 2 & 24.9 & $<0.0001$ \\
& Method & 5 & 179.2 & $<0.0001$
\end{tabular}

Main effects and statistically significant, or near-significant, interactions are shown

${ }^{a}$ Likelihood ratio Chi-squared statistic

or mud walls and iron sheet roofs (Dunn pairwise comparisons: $|Z|>3.5, P<0.0014$ in both cases). In contrast, female yield was not affected by the type of house construction (Kruskal-Wallis: $X^{2}=4.0, P=0.1353$ ) (Table 9).

\section{Discussion}

The mosquito collection methods used in this study proved highly specific to Anopheles mosquitoes. Very few other genera were collected during this investigation other than in occasional mixed swarms during the early rainy season.
Aspiration of eaves (EAV) is a method often ignored in population studies. This study shows that this method can not only provide a sex-balanced catch, but one that is efficient in terms of mosquito yield per man hour. The method does require consent from house owners/ residents but as it does not intrude into private interior space, it may have ethical and practical benefits. For male catches, eave aspiration works effectively and efficiently in areas of traditional grass-roofed housing, although it may be less useful in the suburban and urban areas where thatched roofs are less frequent. In these latter areas it is possible that resting traps, such as buckets and clay pots, will prove to be more rewarding sampling tools for male catches than in the rural context studied here.

Unexpectedly, eave aspiration revealed a spatial coincidence between highly productive aspirated house eaves and independently identified mosquito swarm locations (Fig. 8). Using this observation has enabled reliable prediction of the general location of mosquito swarms in subsequent collections. Further study will be needed to understand whether this is a reliable correlation in other areas. If it proves so, rapidly executed eave sampling is likely to be a useful tool for assisting with locating swarms in future collections and may substantially reduce the challenges of finding mosquito swarms in East Africa.

Bush aspiration (BUSH) showed improved performance in terms of numbers of male mosquitoes collected, 
Table 8 Post-hoc pairwise comparisons (generalized linear model contrasts) of the yield per man hour of A. gambiae female and male mosquitoes collected using the different methods

\begin{tabular}{|c|c|c|c|c|}
\hline Comparison & Value & Log-likelihood & Chi-square & $P$-value \\
\hline \multicolumn{5}{|l|}{ Females } \\
\hline BUSH-ASP & 3.55 & 170.57 & 120.43 & $<0.0001^{*}$ \\
\hline CPT-ASP & 4.24 & 160.08 & 99.46 & $<0.0001^{*}$ \\
\hline CPT-BUSH & 0.69 & 110.58 & 0.45 & $=0.5009$ \\
\hline EAV-ASP & 0.55 & 114.90 & 9.08 & $=0.0026$ \\
\hline EAV-BUSH & -2.10 & 141.44 & 62.17 & $<0.0001^{*}$ \\
\hline EAV-CPT & -3.69 & 137.35 & 53.99 & $<0.0001^{*}$ \\
\hline RBT-ASP & 4.46 & 160.92 & 101.13 & $<0.0001^{*}$ \\
\hline RBT-BUSH & 0.92 & 110.71 & 0.70 & $=0.4015$ \\
\hline RBT-CPT & 0.22 & 137.35 & 0.03 & $=0.8737$ \\
\hline RBT-EAV & 3.91 & 138.06 & 55.41 & $<0.0001^{*}$ \\
\hline SWN-ASP & 6.86 & 159.84 & 98.97 & $<0.0001^{*}$ \\
\hline SWN-BUSH & 3.31 & 111.68 & 2.66 & $=0.1032$ \\
\hline SWN-CPT & 2.62 & 110.86 & 1.02 & $=0.3128$ \\
\hline SWN-EAV & 6.31 & 138.93 & 57.16 & $<0.0001^{*}$ \\
\hline SWN-RBT & 2.39 & 110.73 & 0.76 & $=0.3844$ \\
\hline \multicolumn{5}{|l|}{ Males } \\
\hline BUSH-ASP & 0.86 & 128.38 & 3.48 & $=0.0620$ \\
\hline CPT-ASP & 1.58 & 129.99 & 6.73 & $=0.0095$ \\
\hline CPT-BUSH & 0.72 & 127.17 & 0.30 & $=0.2989$ \\
\hline EAV-ASP & -1.91 & 154.86 & 56.45 & $<0.0001^{*}$ \\
\hline EAV-BUSH & -2.77 & 178.57 & 103.87 & $<0.0001^{*}$ \\
\hline EAV-CPT & -3.49 & 173.20 & 93.13 & $<0.0001^{*}$ \\
\hline RBT-ASP & 1.29 & 129.22 & 5.18 & $=0.0229$ \\
\hline RBT-BUSH & 0.43 & 126.86 & 4.43 & $=0.5006$ \\
\hline $\mathrm{RBT}-\mathrm{CPT}$ & 0.12 & 126.69 & 0.12 & $=0.7311$ \\
\hline RBT-EAV & 3.20 & 170.99 & 88.72 & $<0.0001^{*}$ \\
\hline SWN-ASP & -0.11 & 126.67 & 0.07 & $=0.7933$ \\
\hline SWN-BUSH & -0.96 & 128.85 & 4.43 & $=0.0353$ \\
\hline SWN-CPT & -1.69 & 130.54 & 7.80 & $=0.0052$ \\
\hline SWN-EAV & 1.80 & 150.73 & 48.20 & $<0.0001^{*}$ \\
\hline SWN-RBT & -1.40 & 129.72 & 6.16 & $=0.0131$ \\
\hline
\end{tabular}

*Significant difference between methods

making up 2.54\% (32 mosquitoes) of the total catch at the peak of the rainy season compared to only $0.86 \%$ ( 5 mosquitoes) at the start of the rainy season $\left(\chi^{2}=12.17\right.$, $P=0.033$ ) (Fig. 6). There was a yield per man hour of four mosquitoes during the peak of the rainy season compared to less than one at the start of the season $\left(\chi^{2}<3.14\right.$, $P=0.08$ ) (Fig. 7). Overall bush aspiration remained a disappointing collection method, with very low numbers of male mosquitoes captured. This could be due to the local ecology of these mosquito species where it is possible that they do not prefer to rest in bushes.

Clay pots and buckets used as resting traps have proven successful at capturing both female and male mosquito spp. elsewhere [22, 23], although they were substantially less productive than anticipated during this study. Several factors may have contributed to this: (i) differences in the local Anopheles species composition-previous studies captured mostly $A$. arabiensis while the sites in this study were dominated by $A$. gambiae (s.s.); (ii) the rural villages had an abundance of bushy vegetation and cool eaves to provide the mosquitoes with a plentiful choice of natural resting places; (iii) both types of resting traps were novel in the environment and there may have been residual and potentially unappealing odors from their manufacturing process. Additionally, the resting traps were not left in the study locations for extended periods. Unlike the other methods tested, neither resting trap method proved effective at the peak of the rainy season, which suggests that male mosquito ecology changes when populations are more abundant and mating opportunities more likely. Perhaps in these situations, male mosquitoes select for different resting shelters, such as house eaves. Further evaluation is required to assess whether the poor performance seen here may be attributed to these factors and whether simple additions such as lures might increase their utility in a rural context.

The male-targeted methods used in this study that were able to capture both sex-balanced and male-dominated samples, such as eave aspiration, and the two types of resting traps could greatly improve our understanding of male mosquito ecology in other contexts. The variation in the numbers of female mosquitoes caught by the methods compared in this study could be explained by the combined effect of low absolute numbers of females, relatively low sample sizes and the fact that these methods are explicitly aimed at males.

In the peak of the rainy season, sweep netting of swarms (SWN) was the most effective method for catching substantial numbers of males, with aspiration of eaves (EAV) coming second. However, in the early season this situation was reversed, and the eaves of grass-roofed houses were particularly rewarding. This highlights the importance of method selection for catching male $A$. gambiae (s.l.) mosquitoes and suggests that using several complementary methods may be key to obtaining sufficient numbers for accurate population indices as the seasonal ecology of males varies.

In this study the substantial increase in catch numbers of both males and female mosquitoes at the peak of the rainy season contrasted with the findings of some other studies which found higher population numbers at the start of the rainy season [31-33]. These results suggest that although mosquito populations could be adversely affected by heavy rains, leading to washing away of larvae during peak rainy seasons [32], the formation of additional sites might outweigh the loss 


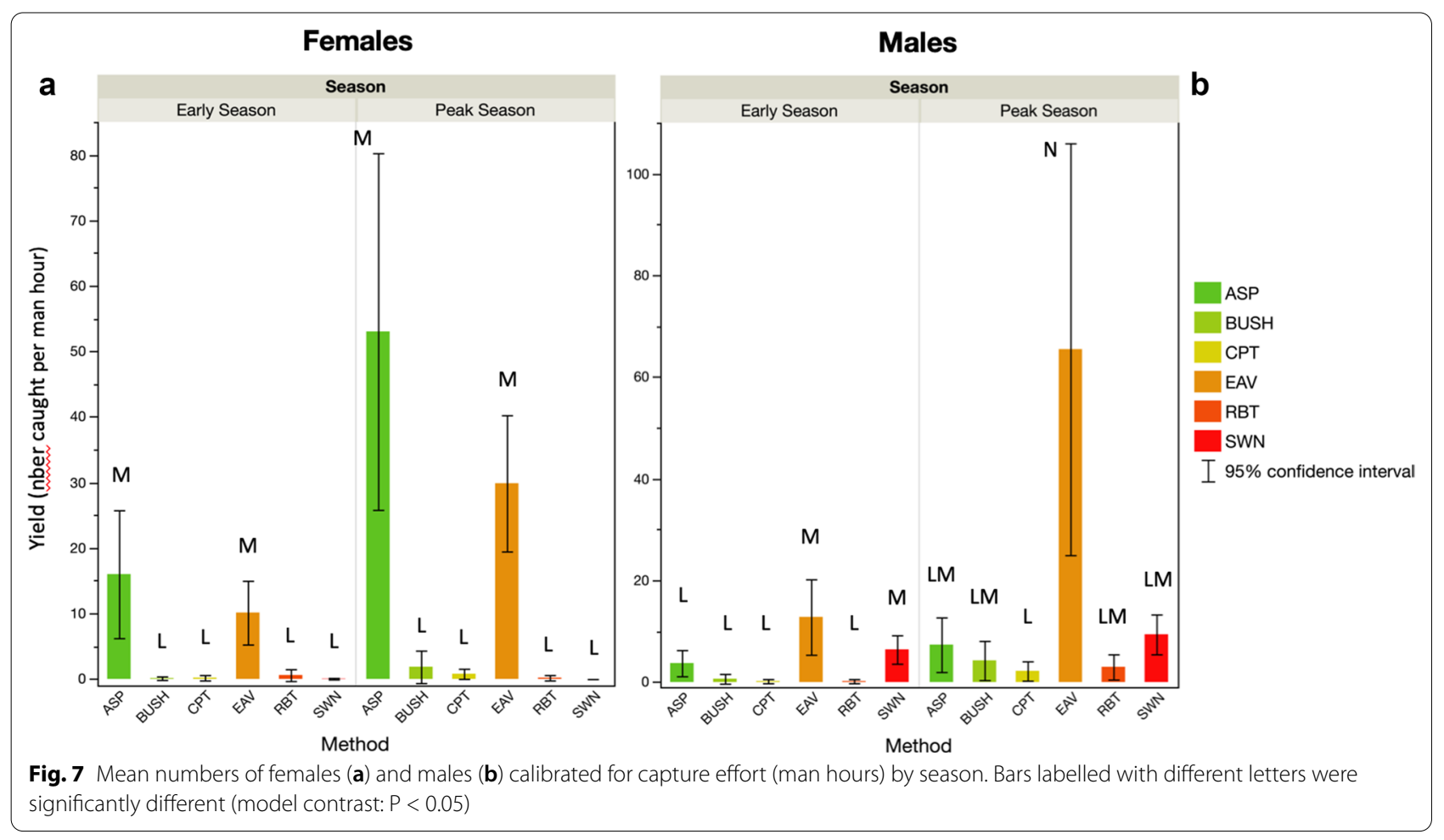

Table 9 Efficiency of the house aspiration methods as a function of house type

\begin{tabular}{llllll}
\hline \multirow{2}{*}{$\begin{array}{l}\text { House } \\
\text { type }\end{array}$} & \multicolumn{2}{l}{ Interior aspiration (ASP) } & & \multicolumn{2}{l}{ Eave aspiration (EAV) } \\
\cline { 2 - 3 } \cline { 5 - 6 } \cline { 5 - 6 } & Male & Female & & Male & Female \\
\hline $\begin{array}{c}\text { Brick/iron } \\
\text { sheet }\end{array}$ & $4.6 \pm 17.1$ & $37.5 \pm 86.7$ & & $1.0 \pm 2.0$ & $16.0 \pm 17.3$ \\
$\begin{array}{c}\text { Mud/grass } \\
\text { thatch }\end{array}$ & $12.0 \pm 14.7$ & $15.5 \pm 23.9$ & & $46.2 \pm 87.9$ & $21.0 \pm 24.7$ \\
$\begin{array}{c}\text { Mud/iron } \\
\text { sheet }\end{array}$ & $4.9 \pm 7.9$ & $37.8 \pm 48.8$ & & $5.3 \pm 9.4$ & $14.7 \pm 21.3$ \\
\hline
\end{tabular}

Efficiency values are presented as the mean total ( \pm standard deviation) number of mosquitoes per man hour

of larvae from pre-existing and potentially washedout sites. It is also possible that there are site-specific rainfall thresholds above which peak-season declines occur. Only time-series data of mosquito numbers and accompanying rainfall data would allow this to be investigated.

All of the male-targeted methods were associated with yields of higher proportions of male A. gambiae mosquitoes when compared to the frequently used indoor aspiration methods. Indoor targeted methods catch many females that are resting after taking blood meals or which are attracted by host odors. This result further affirms that specific male-targeted methods are required to boost male mosquito capture proportions in traditional mosquito population sampling. Of the methods evaluated, swarm collection and aspiration of house eaves offered particular value to sampling designs aimed to give a comprehensive description of the mosquito population dynamics, and demonstrably delivered a higher male proportion than interior aspirations (ASP). These were also the most effective in terms of numbers of individuals captured per unit, indicating that effective sampling for studies and surveillance of anophelines can be predictably achieved through aspiration sampling of a limited number of randomly chosen house eaves or swarms. In contrast, although aspiration of bushes (BUSH) and resting traps (RBTs, CPTs) yielded sex-balanced samples, the results could also require consideration of specific ecological circumstances. The low return per sample would translate into very large numbers of bushes and resting traps being needed to obtain adequate numbers. This would then be logistically cumbersome.

These differences in trapping efficiency and practicality are further highlighted when human resources are taken into account. Many factors contribute to the overall 'effort' of sampling mosquitoes in the field: planning, logistics, stakeholder engagement, staff time, volunteer training, consumables, among others. The metric in this study did not encompass all of these factors and provided only an estimation of the mosquito yield of these methods as a specific function of the field-man hours. 


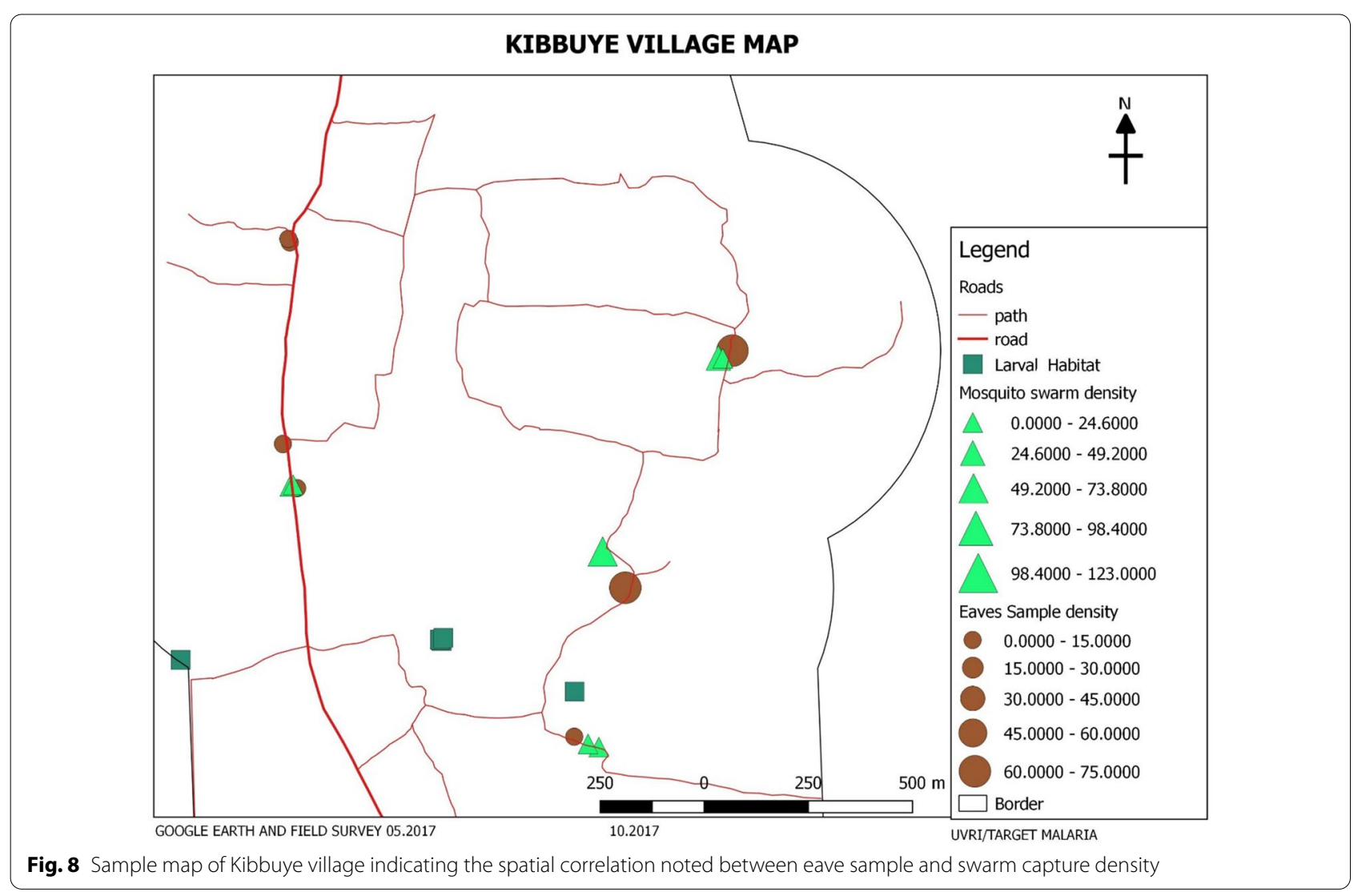

Nonetheless, this value was useful and indicated greater efficiency of male capture at the peak of the rainy season when compared to lower background densities earlier in the season. The same was not true for females, possibly indicating in general a higher efficiency of the methods used for collecting females, especially the female-targeted interior aspiration (ASP) method. However, this is only one possible explanation, and further study would more clearly evaluate the relative efficiency of capture method between sexes and seasons. It was interesting to note that although sweep netting of swarms did catch high numbers, aspiration of grass-roofed houses collected in the villages gave the highest returns of male $A$. gambiae mosquitoes for the least effort. The substantial effort involved in locating and sampling swarms reduced its efficiency relative to other methods. This emphasizes that being clear about requirements is crucial to the planning of sampling. When high numbers are needed, then the effort of swarm sampling may be necessary; if a representative index of males and females is sought, then aspiration of bushes and eaves may serve well.

It can be deduced that the sampling times may be flexible. The paucity of mosquitoes found in afternoon aspiration samples (1 mosquito found in 223 samples) and other methods (EAV, RBT, CPT and BUSH) used to sample a location for a second time on the same day affirm that the mosquitoes did not relocate during the late morning hours. This lack of daytime movement suggests that it may be possible to relax the time at which sampling is performed, or to extend the hours of sampling if conditions permit. Further optimization and experimentation may be required in order to fully understand whether the time of collection does influence the productivity or effectiveness of these methods. While these observations may be of use for those planning sampling, they did not contribute any evidence to the discussion surrounding behavioral shifts of anopheline mosquitoes towards activity earlier in the evening.

The house type of selected sampling units may have been more influential on the catch obtained. The male mosquito catch was greater from the grass thatchroofed houses than from the tin sheeted-roofed ones, but as this was not observed for the female catch it may indicate that different features are attractive to each sex. Females may be drawn by the prospect of blood meals regardless of roof type, whereas males, looking for a resting site for daytime shelter, may find the cooler, and likely less variable, shade of thatched roots more attractive than that of tin roofs. This would affect the selection of an efficient sampling design where 
house type is variable-as can be found in many of the rural villages in Uganda.

\section{Conclusions}

Anopheles gambiae mosquito swarms could be located and used to collect males in Uganda. The mosquito swarm collection method was the most productive male mosquito collection method tested in this study, while house eave aspiration was the most efficient. The clear efficiency of house eave aspiration in delivering a sex-balanced and man-hour efficient catch is extremely useful to the design of mosquito collection experiments. This is particularly true for population studies, such as MRR experiments, and in study designs where sex-balanced results are important. This study provided the useful observation that aspiration of eaves could prove to be a better indicator of $A$. gambiae mosquito swarming locations in East Africa than the identification of physical markers, which is a technique largely informed by West African studies. There are many locations where A. gambiae mosquito swarms remain elusive and further investigation is warranted. Male collection methods are clearly a research direction with plenty of room left for further exploration, innovation, improvement and optimization of available methods. With the progression of new and innovative technologies, such as the sterile insect technique, and active genetics studies which rely on a greater understanding of male mosquito dynamics and behavior, this work is increasingly important and timely.

\section{Abbreviations \\ ASP: Aspiration of house interiors; BUSH: Aspiration of bushes; CPT: Clay pot trap; EAV: Aspiration of house exterior eaves; RBT: Resting bucket trap; SWN: Sweep net collection of swarms.}

\section{Acknowledgements}

We thank the field entomology mosquito collection team in the Entomology Division at UVRI, Brian Ssengendo who assisted with data entry and analysis as a part of his internship and the communities in the villages of Kibbuye, Kayonjo and Katuuso in Uganda where these data were collected. We thank Carol Stimpson for proofreading the manuscript.

\section{Authors' contributions}

$\mathrm{KB}, \mathrm{CMC}, \mathrm{FT}$, and JKK conceived and designed the study; KB and DPM managed the sampling activities; EWC and AN engaged with stakeholders and obtained householder consents and community acceptance for the study; VB conducted laboratory processing; FT, CMC and SK performed data analysis; KB, CMC, FT and JKK contributed to writing and editorial polishing. All authors read and approved the final manuscript.

\section{Funding}

This study was supported by Target Malaria Award number OPP1 141988. Target Malaria receives core funding from the Bill \& Melinda Gates Foundation and from the Open Philanthropy Project Fund, an advised fund of Silicon Valley Community Foundation. JKK at UVRI is also supported in part by: The Government of Uganda, MoH; H3ABioNet (NIH Grant no U24HG006941); and the Makerere University/Uganda Virus Research Institute Centre of Excellence for Infection and Immunity Research and Training (MUII-plus). MUII-plus is supported through the DELTAS Africa Initiative (Grant no. 107743). The DELTAS Africa Initiative is an independent funding scheme of the African Academy of
Sciences (AAS), Alliance for Accelerating Excellence in Science in Africa (AESA) and is supported by the New Partnership for Africa's Development Planning and Coordinating Agency (NEPAD Agency) with funding from the Wellcome Trust (Grant no. 107743) and the UK Government.

\section{Availability of data and materials}

The data are part of a wider study of baseline mosquito abundance across Africa and are available from the corresponding author on reasonable request.

\section{Declarations}

\section{Ethics approval and consent to participate}

Approval for the work was sought and received from the UVRI Research and Ethics Committee (Approval number GC/127/18/01/600) and the study was registered with the Uganda National Council of Science and Technology (Permit number HS 2378). Written consent for sampling inside and under the eaves of houses was obtained for the study period from household owners; their oral consent was reaffirmed at each sampling. Signed community acceptance was obtained from the village local council representatives for the sampling in outdoor community spaces for the rest of the outdoor collection methods which were taking place in community space.

\section{Consent for publication}

Not applicable.

\section{Competing interests}

The authors declare that they have no competing interests.

\section{Author details}

${ }^{1}$ Entomology Division, Uganda Virus Research Institute (UVRI), Plot 51-59, P.O. Box 49, Entebbe, Uganda. ${ }^{2}$ MRC/UVRI \& LSHTM Uganda Research Unit, Plot 51-59, P.O. Box 49, Entebbe, Uganda. ${ }^{3}$ The Centre for Environmental Policy, Imperial College London, The Weeks Building, 16-18 Princes Gardens, London SW7 1NE, UK. ${ }^{4}$ Centre for Applied Entomology and Parasitology, School of Life Sciences, Keele University, Staffordshire ST5 5BG, UK.

Received: 15 February 2021 Accepted: 3 May 2021

Published online: 26 May 2021

\section{References}

1. Steketee RW, Campbell CC. Impact of national malaria control scale-up programmes in Africa: magnitude and attribution of effects. Malar J. 2010;9:299.

2. Tukei BB, Beke A, Lamadrid-Figueroa H. Assessing the effect of indoor residual spraying (IRS) on malaria morbidity in Northern Uganda: a before and after study. Malar J. 2017;16:4

3. Tchouakui M, Mugenzi LMJ, Menze DB, Khaukha JNT, Tchapga W, Tchoupo M, et al. Pyrethroid resistance aggravation in Ugandan malaria vectors is reducing bednet efficacy. Pathogens. 2021;10:415.

4. N'Guessan R, Corbel V, Akogbéto M, Rowland M. Reduced efficacy of insecticide-treated nets and indoor residual spraying for malaria control in pyrethroid resistance area, Benin. Emerg Infect Dis. 2007;13:199-206.

5. Tananchai C, Tisgratog R, Juntarajumnong W, Grieco JP, Manguin S, Prabaripai A, et al. Species diversity and biting activity of Anopheles dirus and Anopheles baimaii (Diptera: Culicidae) in a malaria prone area of western Thailand. Parasites Vectors. 2012;5:211.

6. Kamareddine $L$. The biological control of the malaria vector. Toxins. 2012;4:748-67.

7. Russell TL, Govella NJ, Azizi S, Drakeley CJ, Kachur SP, Killeen GF. Increased proportions of outdoor feeding among residual malaria vector populations following increased use of insecticide-treated nets in rural Tanzania. Malar J. 2011;10:80.

8. Mmbando AS, Okumu FO, Mgando JP, Sumaye RD, Matowo NS, Madumla E, et al. Effects of a new outdoor mosquito control device, the mosquito landing box, on densities and survival of the malaria vector, Anopheles arabiensis, inside controlled semi-field settings. Malar J. 2015;14:494. 
9. Burke A, Dandalo L, Munhenga G, Dahan-Moss Y, Mbokazi F, Ngxongo S, et al. A new malaria vector mosquito in South Africa. Sci Rep. 2017. https://doi.org/10.1038/srep43779.

10. Domingos A, Pinheiro-Silva R, Couto J, do Rosário V, de la Fuente J. The Anopheles gambiae transcriptome-a turning point for malaria control. Insect Mol Biol. 2017;26:140-51.

11. Warrell DA, Gilles HM. Essential malariology. 4th ed. London: CRC Press; 2002.

12. Service MW. Mortalities of the immature stages of species B of the Anopheles gambiae complex in Kenya: comparison between rice fields and temporary pools, identification of predators, and effects of insecticidal spraying. J Med Entomol. 1977;13:535-45.

13. Service MW. Mosquito ecology: field sampling methods. Dordrecht: Springer Netherlands; 1993. https://doi.org/10.1007/978-94-015-8113-4.

14. Beaty BJ, Marquardt WC. In: Beaty BJ, Marquardt WC (eds) The biology of disease vectors. 1st edn. Niwot, Colo: University Press of Colorado; 1996. p. 471-2.

15. Harbison JE, Mathenge EM, Misiani GO, Mukabana WR, Day JF. A simple method for sampling indoor-resting malaria mosquitoes Anopheles gambiae and Anopheles funestus (Diptera: Culicidae) in Africa. J Med Entomol. 2006:43:473-9.

16. Ndiath MO, Mazenot C, Gaye A, Konate L, Bouganali C, Faye O, et al. Methods to collect Anopheles mosquitoes and evaluate malaria transmission: a comparative study in two villages in Senegal. Malar J. 2011;10:270.

17. Lima JBP, Rosa-Freitas MG, Rodovalho CM, Santos F, Lourenço-de-Oliveira R. Is there an efficient trap or collection method for sampling Anopheles darlingi and other malaria vectors that can describe the essential parameters affecting transmission dynamics as effectively as human landing catches? - a review. Mem Inst Oswaldo Cruz. 2014;109:685-705.

18. Dugassa S, Lindh JM, Lindsay SW, Fillinger U. Field evaluation of two novel sampling devices for collecting wild oviposition site seeking malaria vector mosquitoes: OviART gravid traps and squares of electrocuting nets. Parasites Vectors. 2016:9:272.

19. Wahid I, Sunahara T, Mogi M. Maxillae and mandibles of male mosquitoes and female autogenous mosquitoes (Diptera: Culicidae). J Med Entomol. 2003:40:150-8.

20. Krzywinska E, Dennison NJ, Lycett GJ, Krzywinski J. A maleness gene in the malaria mosquito Anopheles gambiae. Science. 2016;353:67-9.

21. International Atomic Energy Agency (IAEA). Male mosquito trapping methods. 2017. https://www.iaea.org/resources/technical-report/malemosquito-trapping-methods. Accessed 9 June 2018.

22. Odiere M, Bayoh MN, Gimnig J, Vulule J, Irungu L, Walker E. Sampling outdoor, resting Anopheles gambiae and other mosquitoes
(Diptera: Culicidae) in western Kenya with clay pots. J Med Entomol. 2007:44:14-22

23. Van den Bijllaardt W, Braak R, Shekalaghe S, Otieno S, Mahande A, Sauerwein $\mathrm{R}$, et al. The suitability of clay pots for indoor sampling of mosquitoes in an arid area in northern Tanzania. Acta Trop. 2009;111:197-9.

24. Uganda Ministry of Health and the Ministry of Finance, Planning and Economic Development. The Uganda malaria reduction strategic plan 2014-2020. https://www.health.go.ug/cause/the-uganda-malaria-reduc tion-strategic-plan-2014-2020/. Accessed 9 June 2018.

25. Medlock J, Balenghien T, Alten B, Versteirt V, Schaffner F. Field sampling methods for mosquitoes, sandflies, biting midges and ticks. EFSA Support Publ. 2018;15(6):1435E. https://doi.org/10.2903/sp.efsa.2018.EN-1435.

26. Kreppel KS, Johnson PCD, Govella NJ, Pombi M, Maliti D, Ferguson HM. Comparative evaluation of the Sticky-Resting-Box-Trap, the standardised resting-bucket-trap and indoor aspiration for sampling malaria vectors. Parasites Vectors. 2015;8:462.

27. Diabaté A, Dao A, Yaro AS, Adamou A, Gonzalez R, Manoukis NC, et al. Spatial swarm segregation and reproductive isolation between the molecular forms of Anopheles gambiae. Proc Biol Sci. 2009;276:4215-22.

28. Gillies MT, Coetzee M. A supplement to the Anophelinae of Africa, south of the Sahara (Afrotropical region). Johannesburg: South African Institute for Medical Research; 1987

29. Wilkins EE, Howell PI, Benedict MQ. IMP PCR primers detect single nucleotide polymorphisms for Anopheles gambiae species identification, Mopti and Savanna rDNA types, and resistance to dieldrin in Anopheles arabiensis. Malar J. 2006;5:125.

30. SAS Institute Inc. JMP ${ }^{\circledR}$ 1989-2019. Cary: SAS Institute Inc.

31. Jawara M, Pinder M, Drakeley CJ, Nwakanma DC, Jallow E, Bogh C, et al. Dry season ecology of Anopheles gambiae complex mosquitoes in the Gambia. Malar J. 2008;7:156.

32. Paaijmans KP, Wandago MO, Githeko AK, Takken W. Unexpected high losses of Anopheles gambiae larvae due to rainfall. PLOS ONE. 2007;2:e1146.

33. Bier J, Copeand R, Oyaro C, Masinya A, Odago WO, Oduor S, et al. Anopheles gambiae complex egg-state survival in dry soil from larval development sites in western Kenya. J Am Mosq Control Assoc. 1990;6:105-9.

\section{Publisher's Note}

Springer Nature remains neutral with regard to jurisdictional claims in published maps and institutional affiliations.
Ready to submit your research? Choose BMC and benefit from:

- fast, convenient online submission

- thorough peer review by experienced researchers in your field

- rapid publication on acceptance

- support for research data, including large and complex data types

- gold Open Access which fosters wider collaboration and increased citations

- maximum visibility for your research: over 100M website views per year

At BMC, research is always in progress.

Learn more biomedcentral.com/submissions 